\title{
Clinical and differential utility of VEGF inhibitors in wet age-related macular degeneration: focus on aflibercept
}

This article was published in the following Dove Press journal:

Clinical Ophthalmology

25 July 2012

Number of times this article has been viewed

\author{
Michael W Stewart \\ College of Medicine, Mayo Clinic, \\ Jacksonville, FL, USA
}

Correspondence: Michael W Stewart Department of Ophthalmology, 4500 San Pablo Road, Jacksonville, FL 32224, USA

Tel +l 9049532232

Fax + I 9049537040

Email stewart.michael@mayo.edu

\begin{abstract}
Age-related macular degeneration (AMD) has become a major public health problem and a leading cause of blindness in industrialized nations. AMD results from the ageing eye's inability to metabolize and dispose completely of photoreceptor outer segments and other waste products. As a result, lipids, particularly apolipoproteins, accumulate within Bruch's membrane, leading to chronic ischemia and inflammation. The subsequent upregulation of inflammatory cytokines and growth factors, including vascular endothelial growth factor (VEGF), induces the growth of neovascular membranes from the choriocapillaris into the subretinal or subretinal pigment epithelium spaces. To counter this, intravitreally administered drugs (pegaptanib, bevacizumab, ranibizumab) that specifically target VEGF have become the standard treatment for exudative AMD. Aflibercept, a recently approved fusion protein, binds to all isoforms of both VEGF-A and placental growth factor with high affinity. Phase III trials showed that monthly or every other month injections of aflibercept prevent vision loss (fewer than 15 letters) in $95 \%$ of patients. Additionally, aflibercept injections every 4 or 8 weeks produce average vision gains of 6.9 letters to 10.9 letters, comparable with those achieved with monthly ranibizumab. After one year of regularly administered aflibercept injections, patients required an average of only 4.2 injections during the second year. Aflibercept promises to decrease the injection frequency required for many patients and appears to serve as an effective "salvage" therapy for patients who respond poorly to other anti-VEGF drugs.
\end{abstract}

Keywords: age-related macular degeneration, choroidal neovascularization, vascular endothelial growth factor, aflibercept, ranibizumab, bevacizumab, VEGF trap

\section{Introduction}

Age-related macular degeneration (AMD) is the leading cause of blindness in patients over the age of 65 years in industrialized nations. Most affected patients (approximately $90 \%$ ) have dry or nonexudative AMD, characterized by drusen and retinal pigment epithelium (RPE) mottling, hyperplasia, and atrophy, but most cases of blindness (approximately 90\%) are due to wet or exudative AMD, which is characterized by the growth of choroidal neovascular membranes (CNVM). ${ }^{1}$ Wet AMD results from repeated cycles of shedding, degradation, and resynthesis of photoreceptor outer segments, which induces metabolic stress within the outer retina and RPE. The resultant chronic ischemia and inflammation upregulates several inflammatory cytokines and growth factors, particularly vascular endothelial growth factor (VEGF), which promote the growth of CNVM from the choriocapillaris into the sub-RPE space (type 1 CNVM), the subretinal space (type 2 CNVM), or the inner retina as retinal angiomatous proliferation (type $3 \mathrm{CNVM}$ ). 
The treatment of exudative AMD has evolved considerably over the past 40 years, but the visual outcomes throughout most of this period have disappointed both patients and physicians. Thermal laser photocoagulation, as performed in the Macular Photocoagulation Study, slowed the rate of vision loss, but was complicated by recurrent neovascularization, and frequently left patients with dense scotomas. ${ }^{2}$ Photodynamic therapy with intravenous verteporfin decreased the extent of photoreceptor and RPE scarring, but still resulted in vision loss for most patients. ${ }^{3}$

Only with the introduction of drugs that directly inhibit the actions of VEGF have surgeons been able to offer patients reasonable hope for improvement of vision. Pivotal trials with ranibizumab, bevacizumab, and aflibercept show that patients receiving protocol-driven treatment have a $30 \%-40 \%$ chance of achieving a 15 -letter (halving of the visual angle) improvement in visual acuity. ${ }^{4-7}$ The rapid adoption of these drugs by physicians has yielded dramatic improvements in public health. Between 2000 and 2010, anti-VEGF therapy resulted in a $50 \%$ reduction in the incident rate of blindness due to exudative AMD in Denmark, compared with a $33 \%$ reduction in the incidence of blindness from other causes. ${ }^{8}$

Three anti-VEGF drugs have been used for over 5 years, i.e. pegaptanib (Macugen ${ }^{\circledR}$; Eyetech Inc, Palm Beach Gardens, FL, introduced in 2004), bevacizumab (Avastin ${ }^{\circledR}$; Genentech, South San Francisco, CA/Roche, Basel, Switzerland, first used off-label in 2005) and ranibizumab (Lucentis $^{\circledR}$; Genentech, South San Francisco, CA/Roche, Basel, Switzerland, introduced in 2006), whereas aflibercept (VEGF Trap-eye, Eylea ${ }^{\circledR}$; Regeneron, Tarrytown, NY) has been available only since being granted regulatory approval for the treatment of exudative AMD by the United States Food and Drug Administration on November 18, 2011. This paper discusses the pathophysiology of exudative AMD with emphasis on the stimulatory role of VEGF, the biochemical and pharmacologic characteristics of aflibercept, and the results of important clinical trials focusing on the treatment of patients with exudative AMD.

\section{Pathophysiology of AMD}

Untreated CNVM due to AMD carries a poor prognosis with $62 \%$ of subfoveal membranes and $65 \%$ of juxtafoveal membranes causing profound (more than 6 lines) loss of vision. ${ }^{9} 10$ Treatment according to MPS guidelines limits vision loss in some patients, but $87 \%$ of eyes with CNVM do not qualify for laser, ${ }^{11}$ and furthermore, only $18 \%$ of patients qualify for ocular photodynamic therapy. ${ }^{12}$
These sobering results underscore the need for both an improved understanding of the pathophysiology of AMD and a non-destructive therapy that can be given to the majority of affected patients.

The earliest observable signs of AMD include mild atrophy and hypertrophy of the RPE, along with the formation of drusen. In addition to the development of confluent soft drusen, decreased choroidal blood flow, lipid deposition in Bruch's membrane, oxidative stress in the RPE, and alteration in Bruch's membrane all contribute to ischemia of the overlying RPE, secondary death of cells in the neural retina, and, finally to induction of CNVM. ${ }^{13-18}$ Whereas drusen and RPE atrophy generally cause a slow decrease in vision, a rapid decline usually accompanies the development of CNVM. ${ }^{19}$

The pathophysiology of AMD actually begins with lipoprotein transport of carotenoids, vitamin E, and cholesterol to the photoreceptors through the RPE (Figure 1). ${ }^{20,21}$ Nutrients are separated within the RPE and presented to the photoreceptors while, at the same time, the RPE performs near continuous, homeostatic phagocytosis of photoreceptor outer segments, ${ }^{22-24}$ with assembly of apolipoprotein B from phagocytosed photoreceptor outer segments, plasma lipoprotein components, and endogenously synthesized lipids. With advancing age comes metabolic insufficiency which causes a decrease in protein and lipid degradation within the RPE. This results in accumulation of lipofuscin within lysozymes and a compromised ability to process photoreceptor outer segments and cytoplasmic proteins..$^{25-28}$ With the use of fundus autofluorescence imaging, lipofuscin accumulation within RPE cells has actually been identified prior to observable RPE damage. ${ }^{29,30}$

During the fourth decade of life, unprocessed lipid slowly exits the RPE cells. Most molecules reach the systemic circulation via the choriocapillaris but, for unknown reasons, several layers of apolipoprotein slowly accumulate within Bruch's membrane. Both esterified and nonesterified cholesterol forms small vesicles within membrane fibrils. ${ }^{31,32} \mathrm{~A}$ wall of lipid material, high in several apolipoproteins including apolipoprotein-B, E, A-I, C-I, and C-II, accumulates within Bruch's membrane in a pattern consistent with secretion by the RPE rather than by the choriocapillaris. Over time, proinflammatory molecules, such as linoleate hydroperoxide and 7-ketocholesterol appear, probably as a result of overlying oxidative stress of the RPE.

As the highly demanding metabolic process within the photoreceptors and RPE continues, but oxygen diffusion from the choriocapillaris through the altered Bruch's 

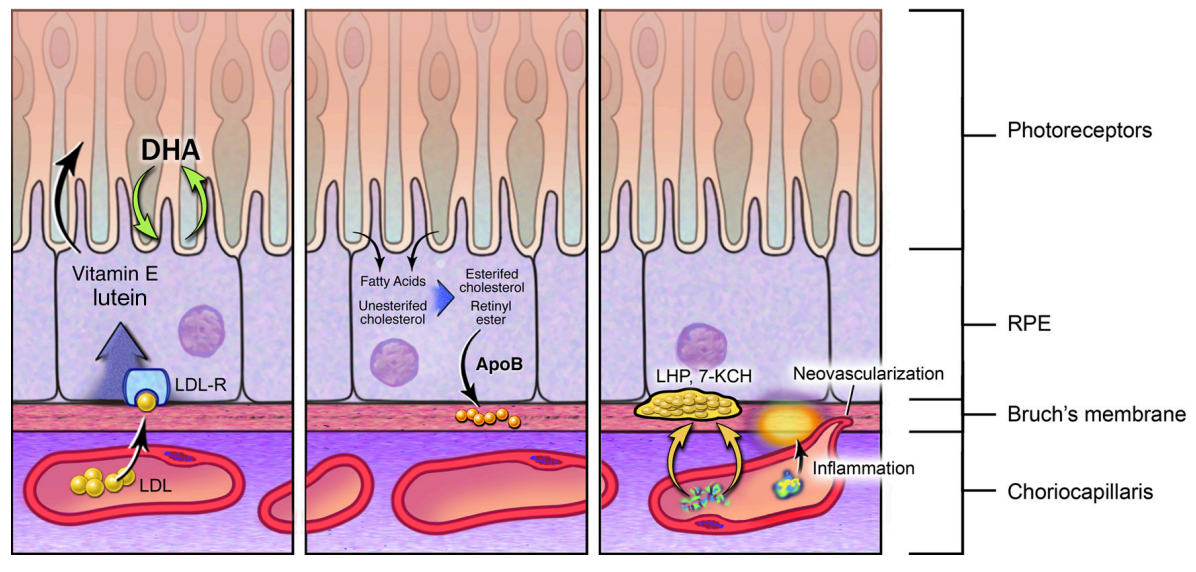

Figure I Left panel: carotenoids, vitamin E and cholesterol are delivered to the retinal pigment epithelium from the choriocapillaris. After initial processing within the retinal pigment epithelium, these molecules are presented to the photoreceptors. Central panel: continuous shedding of photoreceptor outer segments results in high levels of cholesterol and other lipids within the retinal pigment epithelium which, because of decreasing peroxisome activity with advancing age, are only partially metabolized. These are secreted toward the choriocapillaris, but some, particularly apolipoprotein B, accumulate within Bruch's membrane. Right panel: lipid accumulation within Bruch's membrane induces inflammation and ischemia, resulting in neovascular sprouting from the choriocapillaris.

Abbreviations: ApoB, apolipoprotein-B, LDL-R, receptor-bound low density lipoprotein, LHP, linoleate hydroperoxide.

membrane decreases, the resultant oxidative stress produces reactive oxygen species, which leads to protein misfolding. ${ }^{33}$ Additionally, lipofuscin contains vitamin A-derived photophores that inhibit mitochondrial respiration and cause misfolding of proteins. ${ }^{34}$ The RPE is highly dependent upon proper folding of proteins for optimal function, so improperly folded proteins react with heat shock proteins to facilitate repair. ${ }^{35,36}$ If this fails, the folded proteins are tagged with ubiquitin and directed to the proteosomes for degradation. ${ }^{37,38}$ However, because proteosomal function also decreases with age and under conditions of increased oxidative stress, the buildup of improperly folded proteins results in the release of proinflammatory cytokines, which leads to chronic inflammation and the formation of drusen. ${ }^{39}$ In addition to inducing the formation of reactive oxygen species, lipofuscin decreases lysozomal integrity, induces peroxidation, decreases phagocytosis, and promotes RPE death. ${ }^{40,41}$ Apoptotic cell death is further enhanced by the presence of advanced glycation end products which activate their receptors (RAGE) ${ }^{42,43}$ and upregulate nuclear factorkB. ${ }^{44}$ Additionally, RAGE upregulates VEGF which leads to the development of CNVM. ${ }^{45}$

Inflammation plays an important role in promoting angiogenesis through the innate immune system. Membrane-bound toll-like receptors and cytosolic NOD-like receptors are responsible for detecting invading pathogens and directing a compensatory inflammatory response. Toll-like receptors recognize breakdown products of the intercellular matrix (elastin, hyaluronic acid, and fibronectin) and induce the expression of proinflammatory cytokines (interleukins 6 and 8), angiogenic chemokines (CXCL8 and CCL2), and adhesion molecules
(ICAM-1 and VCAM-1). ${ }^{46-50}$ These cytokines further increase production of reactive oxygen species and oxidative stress on the RPE..$^{51,52}$ Activation of NOD-like receptors, through oxidative stress and lysozomal damage, leads to release of interleukin-1B and interleukin-18. ${ }^{53}$

Choroidal dendritic cells become activated by damaged RPE and oxidized protein and lipid in Bruch's membrane. ${ }^{54}$ Activated dendritic cells promote secretion of immune response modulators such as apolipoprotein $\mathrm{E}$ and vibronectin from the RPE and initiate an autoimmune response with production of antiretinal and anti-RPE antibodies. ${ }^{55,56}$ Additionally, inflammatory cells, including multinucleated giant cells, which are involved in the late stages of AMD, secrete enzymes which degrade Bruch's membrane, and cytokines which promote the growth of CNVM. ${ }^{57,58}$

Eventually, chronic ischemia of the outer retina and inflammation directed against abnormalities in Bruch's membrane result in the development of pathologic new blood vessels or angiogenesis. The growth of neovascular complexes requires sequential activation of several biochemical pathways, with upregulation of multiple growth factors, balanced with downregulation of key angiostatic molecules. Angiogenesis plays an important role in several disparate human diseases, including tumor growth and metastases, rheumatoid arthritis, psoriasis, and intraocular neovascularization of both the choroid and retina.

Several growth factors contribute to the development of choroidal neovascularization. Basic fibroblastic growth factor has been detected in excised $\mathrm{CNVM}^{59,60}$ and has been found to be sufficient ${ }^{61,62}$ but not necessary for the development of experimental CNVM. ${ }^{63}$ 
In addition to increased concentrations of growth factors, angiogenesis requires decreased levels of angiostatic molecules. ${ }^{64}$ Pigment epithelium-derived growth factor (PEDF) leads to regression of neovascularization by promoting apoptosis of vascular endothelial cells. ${ }^{65,66}$ PEDF synthesis is upregulated under hyperemic conditions and downregulated in hypoxia. ${ }^{67}$ PEDF levels have been found to be low within choroidal neovascular tissues, ${ }^{68,69}$ and expression of PEDF is inversely correlated with the formation of CNVM in animal models. ${ }^{70}$

Angiopoietins regulate vascular integrity and also participate in pathologic neovascularization. ${ }^{71}$ Angiopoietin-1 prevents leakage from the adult vasculature ${ }^{72}$ whereas angiopoietin-2, which is upregulated in vascular endothelial cells by both hypoxia and $\mathrm{VEGF},{ }^{73}$ enhances the vasoproliferative effects of VEGF. The opposite effects of these two closely related molecules are due to their agonist and antagonist effects on the Tie 2 receptor, which recruits pericytes and stabilizes new blood vessels.

Although other growth factors can induce development of blood vessels (ie, transforming growth factor- $\beta$, interleukins, insulin-like growth factor-1, and epidermal growth factor), only VEGF appears to be both sufficient and essential for both physiologic and pathologic angiogenesis. Not surprisingly, the biochemical pathways involving VEGF have been the most intensively studied and are the best understood.

Oxidative stress and inflammation due to accumulation of intracellular and extracellular waste material, including lipid in Bruch's membrane and drusen, stimulate VEGF synthesis. Excessive local production of VEGF causes multifocal sprouting of new vascular complexes from the choriocapillaris, with growth occurring beneath the RPE, or through the RPE into the subretinal space. ${ }^{74,75}$ The resultant serous detachment of the retina or RPE, often with associated hemorrhage, leads to neuroretinal dysfunction and late gliosis, fibrosis, and cell death. ${ }^{76}$

Autopsies show that VEGF is expressed in the RPE of eyes with AMD, and VEGF has been detected in surgically excised CNVM. ${ }^{77-80}$ Animal models that overexpress VEGF are characterized by the growth of CNVM. ${ }^{81-83}$ VEGF levels are elevated in the vitreous of eyes with exudative AMD. ${ }^{84,85}$

\section{Vascular endothelial growth factor}

VEGF is a member of the platelet-derived growth factor family, ${ }^{86}$ and is actually a collection of related molecules that segregate into distinct families, i.e. VEGF-A VEGF-B, VEGF-C, VEGF-D, VEGF-E, and placental growth factor.
Native VEGF (of which VEGF ${ }_{165}$ appears to be the dominant isomer) exists as a homodimer with a molecular weight between $35 \mathrm{kDa}$ and $45 \mathrm{kDa} .{ }^{87}$

Isoforms of VEGF-A are responsible for most of the processes essential in angiogenesis, i.e. endothelial cell proliferation and migration, recruitment of endothelial cell progenitors, endothelial cell survival, activation of matrix metalloproteinases, and phosphorylation of tight junction proteins. At least six major isoforms $\left(\mathrm{VEGF}_{121}, \mathrm{VEGF}_{145}\right.$, $\mathrm{VEGF}_{165}, \mathrm{VEGF}_{183}, \mathrm{VEGF}_{189}, \mathrm{VEGF}_{206}$ ) and eight minor isoforms of VEGF-A, all created by alternate splicing of mRNA from the same VEGF gene, have been discovered. ${ }^{88}$ Shorter isoforms are water-soluble and biologically active whereas longer isoforms are bound to the intercellular matrix (VEGF ${ }_{165}$ is $50 \%-70 \%$ matrix bound) and only become biologically active when cleaved by matrix metalloproteinase- 9 and plasmin into soluble $\mathrm{VEGF}_{110}$. VEGF-A isoforms contain their receptor binding sequences in amino acids 81 through 92 and their heparin binding sequences within amino acids 110-165.

VEGF initiates its biological effects by binding to three transmembrane receptors, VEGFR1 (flt-1), VEGFR2 (flk-1), and VEGFR3 (flk-4), which are expressed on vascular endothelial cells and pericytes, as well as on monocytes and macrophages ${ }^{89,90}$ Normal choriocapillaris expresses all of its receptors on the endothelial cells next to the RPE, suggesting a codependent paracrine relationship between the two tissues. ${ }^{91}$ Each receptor has extracellular binding domains for VEGF, a transmembrane sequence and intracellular tyrosine kinase moieties. VEGF binding to the extracellular receptor domain dimerizes the receptors and results in phosphorylation of the intracellular tyrosine kinase moieties. VEGFR1 activation by VEGF-A, VEGF-B, and placental growth factor attracts mononuclear leukocytes and promotes development of myocardial arterioles. The role of VEGFR1 in promoting noncoronary angiogenesis is not clear, but it may be a weak angiogenic mediator or may serve as a decoy receptor by binding placental growth factor, thereby displacing VEGF-A and allowing it to bind to and activate VEGFR2. VEGFR1 appears to assist endothelial cell assembly into vascular tubules.

In the retina, VEGF upregulation in RPE, Mueller cells, pericytes, endothelial cells, glial cells, and ganglion cells ${ }^{92}$ is caused by inflammation (interleukins, transforming growth factor alpha and beta) and several growth factors (fibroblastic growth factor, epidermal growth factor, keratinocyte growth factor, insulin-like growth factor-1, and platelet-derived growth factor). However, the usual regulator 
of VEGF synthesis in chorioretinal vascular conditions is tissue hypoxia. Low tissue oxygen tension enables hypoxia inducible factor 1-alpha to dimerize with hypoxia inducible factor 1-beta, thereby preventing complex formation with the von Hippel Lindau factor and subsequent ubiquination within proteosomes. The stable hypoxia inducible factor dimer binds to the promoter zone of VEGF mRNA and upregulates VEGF synthesis. Reactive oxygen species and advanced glycation end products can stimulate the RPE to upregulate VEGF. ${ }^{93,94}$ Hypoxic RPE cells have also been shown to produce placental growth factor which has been detected within CNVM.

Activation of VEGFR2 by VEGF-A is necessary for many critical processes of physiologic and pathologic angiogenesis. Activated VEGFR2 upregulates nitric oxide synthase which promotes vascular endothelial cell proliferation. ${ }^{95}$ By upregulating matrix metalloproteinases and tissue-type plasminogen activators, and downregulating metalloproteinase inhibitors, VEGF degrades the intercellular matrix, thereby enabling endothelial cell migration. ${ }^{76,96}$ Matrix degradation causes the release of previously sequestered VEGF, thereby amplifying the proliferative drive. ${ }^{97} \mathrm{VEGF}$ breaks down the blood retinal barrier by phosphorylating tight junction proteins, forming transcellular vesicles, and creating fenestrations. ${ }^{98}$ Compared with the hyperpermeability effect of histamine, that of VEGF is 50,000 times as potent. ${ }^{61}$ By activating VEGFR1, VEGFA attracts monocytes and macrophages. VEGF is a potent survival factor because it prevents apoptosis of endothelial and glial cells. ${ }^{99}$

\section{Aflibercept biochemistry and pharmacokinetics}

When creating a high-affinity VEGF-binding protein, scientists at Regeneron decided not to use the antibody technology used to create bevacizumab $\left(\mathrm{K}_{\mathrm{d}} 58 \mathrm{pM}\right)$ or the affinityenhanced ranibizumab $\left(\mathrm{K}_{\mathrm{d}} 46 \mathrm{pM}\right){ }^{100}$ Instead they spliced native receptor sequences from high-affinity VEGFR1 $\left(\mathrm{K}_{\mathrm{d}}\right.$ $10-20 \mathrm{pM}$ ) onto the Fc (fragment crystallizable) portion of a human IgG1 molecule. They first created a "parent" VEGF Trap $_{\text {RIRIR1 }}$ with three binding domains from VEGFR1 which tightly bound $\mathrm{VEGF}_{165}$, but exhibited poor serum pharmacokinetics because it was immediately sequestered within the intercellular matrix. After other intermediate molecules were tested, VEGF Trap ${ }_{\text {R1R2 }}$ (aflibercept) was created. With the second binding domain from VEGFR1 and the third binding domain from VEGFR2, this molecule exhibited excellent in vivo pharmacokinetics, with a strong binding affinity for $\mathrm{VEGF}_{165}\left(\mathrm{~K}_{\mathrm{d}} 0.5 \mathrm{pM}\right)$, exceeding even that of the native receptors. ${ }^{101}$ Whereas bevacizumab can simultaneously bind two VEGF dimers, and two ranibizumab molecules can bind one VEGF dimer, aflibercept tightly binds VEGF-A and placental growth factor dimers in a 1 to 1 ratio with a powerful "two-fisted grasp".

The time-dependent intraocular concentration of aflibercept, like that of bevacizumab and ranibizumab, decreases according to first-order decay kinetics. The intravitreal half-life of aflibercept in rabbits is 4.7 days (Regeneron investigator manual), and although monkey and human data are not available, an adapted mathematical model calculates the half-life in human eyes to be 7.1 days. ${ }^{102}$ Because the intraocular half-lives of macromolecules are primarily determined by their molecular weight, that of aflibercept (molecular weight $115 \mathrm{kDa}$ ) should fall between bevacizumab (molecular weight $149 \mathrm{kDa} ; \mathrm{t}_{1 / 2} 8.25$ days) and ranibizumab (molecular weight $48 \mathrm{kDa} ; \mathrm{t}_{1 / 2} 4.75$ days, estimated). ${ }^{102}$ Based on its high binding affinity and estimated intraocular half-life, mathematical modeling suggests that intravitreally administered aflibercept should have a longer duration of clinical action (possibly as long as 2.5 months) than either ranibizumab or bevacizumab. ${ }^{103}$

Aflibercept is believed to diffuse through the eye without being metabolized and enters the systemic circulation through either the choriocapillaris or trabecular meshwork. The half-life of unbound aflibercept is 1-3 days in the blood, whereas VEGF-bound aflibercept has a half-life of 18 days. Aflibercept is removed from the body via pinocytotic proteolysis and glomerular filtration after forming complexes with VEGF. ${ }^{104}$

\section{Preclinical and clinical studies}

Studies with animal models of corneal, iris, retina, and choroidal neovascularization have shown that VEGF plays a central role in pathologic ocular neovascularization. In a matrigel model, aflibercept successfully prevented the growth of CNVM when administered 2 and 6 days after induction, and prevented leukocyte infiltration and halted collagen synthesis within CNVM when administered 10 days after induction. ${ }^{105}$ In mice, aflibercept prevented CNVM following laser photocoagulation to the RPE, prevented CNVM development after administration of exogenous VEGF, and prevented development of CNVM in transgenic animals that secreted VEGF from photoreceptors. ${ }^{106}$ Aflibercept extends the survival of penetrating keratoplasties in mice ${ }^{107}$ and prevents induction of corneal neovascularization after treatment with fibroblast growth factor pellets. ${ }^{108}$

The successes achieved in these preclinical studies paved the way for aflibercept trials in human chorioretinal 
conditions (Table 1). In the first exudative AMD trial, intravenous aflibercept doses between $0.3 \mathrm{mg} / \mathrm{kg}$ and $3 \mathrm{mg} / \mathrm{kg}$ (the usual oncologic dose is $4 \mathrm{mg} / \mathrm{kg}$ ) were administered every 2 weeks to 25 patients. ${ }^{109}$ Macular thickness improved by an average of $66 \%$ and improvements in vision were modest. Because two of five patients receiving the highest drug dose suffered dose-limiting hypertension and proteinuria, all subsequent intravenous administration of aflibercept was limited to oncology, because ophthalmology trials transitioned to intravitreal injections.

The Phase I CLEAR-IT 1 (Clinical Evaluation of Antiangiogenesis in the Retina Intravitreal Trial) investigation was designed to determine the safety, tolerability, maximum tolerated dose, and bioactivity of intravitreally administered aflibercept in patients with exudative AMD. ${ }^{110}$ Single doses of aflibercept between $0.05 \mathrm{mg}$ and $4 \mathrm{mg}$ were tolerated well by 21 patients. At 6 weeks after the injections, patients experienced mean visual acuity gains of +4.4 letters and macular thickness changes of $-104 \mu \mathrm{m}$. Of six patients followed for 12 weeks, three did not require additional injections.

Based on the results of CLEAR-IT 1, the developers hoped to show that aflibercept could be dosed less often than monthly. The Phase II CLEAR-IT 2 trial randomized 159 patients to receive three injections of $0.5 \mathrm{mg}$ or $2 \mathrm{mg}$, or single doses of $0.5 \mathrm{mg}, 2 \mathrm{mg}$, or $4 \mathrm{mg}$, with final evaluations at 12 weeks. At 12 weeks, the average macular thickness improved by $-119 \mu \mathrm{m}$ from baseline $(P<0.0001)$ although the reduction experienced by the patients receiving injections every 4 weeks exceeded that of patients treated only once. At 12 weeks, the average vision in all groups improved by +5.7 letters $(P<0.0001)$, with the greatest improvement (more than eight letters) in patients treated monthly. Visual improvement at week 8 was similar in patients receiving single doses or three doses. ${ }^{111}$

During the second phase of the CLEAR-IT 2 study, patients were followed from week 16 through 52 and given injections as needed. ${ }^{112}$ An average of two injections was required, with a mean time to first injection of 129 days. At week 52, the average improvement in vision compared with baseline (week 0 ) was +5.3 letters $(P<0.0001)$, but patients initially treated with 2 mg every 4 weeks achieved an average improvement of +9 letters. The area covered by the CNVM decreased by an average of $2.21 \mathrm{~mm}^{2}$ at 48 weeks. The CLEAR-IT 2 study demonstrated that patients treated as needed required few injections, yet maintained excellent gains in vision. Additionally, patients receiving three monthly "loading" doses achieved superior visual results compared with those receiving single injections.
Table I Summary of results of the pivotal aflibercept trials. Phase I featured an intravenous trial followed by an intravitreal dose-escalation trial. Phase II featured an initial multiple dose and interval, protocol-directed treatment period ( 12 weeks) followed by a longer period with treatment administered as needed (weeks I6 through 52). Phase III featured two concurrent 52 week trials, VIEW I and VIEW 2

\begin{tabular}{|c|c|c|}
\hline Trial & $\begin{array}{l}\text { Treatment } \\
\text { and patients }\end{array}$ & Key results \\
\hline $\begin{array}{l}\text { Phase I } \\
\text { Intravenous } \\
\text { aflibercept }\end{array}$ & $\begin{array}{l}\text { Placebo: } 6 \\
\text { Aflibercept: } 19 \\
\text { Single dose } \\
\text { followed by } \\
3 \text { doses q2wk of } \\
0.3 \mathrm{mg} / \mathrm{kg} \mathrm{(7)} \\
1.0 \mathrm{mg} / \mathrm{kg}(7) \\
3.0 \mathrm{mg} / \mathrm{kg} \mathrm{(5)}\end{array}$ & $\begin{array}{l}\text { Mean } \% \Delta \text { in excess thickness } \\
\text { at day I5: } \\
\text { Placebo: }-12 \% \\
0.3 \mathrm{mg} / \mathrm{kg}:-10 \% \\
1.0 \mathrm{mg} / \mathrm{kg}:-66 \% \\
3.0 \mathrm{mg} / \mathrm{kg}:-60 \% \\
* 2 / 5 \mathrm{patients} \text { receiving } 3.0 \mathrm{mg} / \mathrm{kg} \\
\text { developed hypertension and } \\
\text { proteinuria }\end{array}$ \\
\hline $\begin{array}{l}\text { Phase I } \\
\text { Intravitreal } \\
\text { aflibercept }\end{array}$ & $\begin{array}{l}\text { Aflibercept: } 2 \text { I } \\
\text { Single injection of } \\
0.05 \mathrm{mg} \mathrm{(3)} \\
0.15 \mathrm{mg} \mathrm{(3)} \\
0.5 \mathrm{mg} \mathrm{(3)} \\
\mathrm{I} \mathrm{mg} \mathrm{(6)} \\
2 \mathrm{mg} \mathrm{(3)} \\
4 \mathrm{mg} \mathrm{(3)}\end{array}$ & $\begin{array}{l}\text { Mean } \Delta \text { thickness at } 6 \text { wks: } \\
-104.5 \mu \mathrm{m} \\
\text { Mean } \Delta \mathrm{VA} \text { at } 6 \text { wks: }+4.43 \text { letters } \\
\text { For } 2 \mathrm{mg} \text { and } 4 \mathrm{mg} \text { groups: } \\
\text { Mean } \Delta \mathrm{VA} \text { at } 6 \text { wks: }+13.5 \text { letters }\end{array}$ \\
\hline
\end{tabular}

$\begin{array}{lll}\text { Phase 2 } & \text { Aflibercept: I59 } & \text { Mean } \Delta \text { thickness at I2 wks: } \\ \text { (CLEAR-IT 2) } & \text { Single injection of } & -119 \mu \mathrm{m} \\ \text { Intravitreal } & 0.5 \mathrm{mg} & \text { (monthly }>\text { single injections) } \\ \text { aflibercept } & 2 \mathrm{mg} & \text { Mean } \Delta \text { VA at I2 wks: }+5.7 \text { letters } \\ 0-12 \text { weeks } & 4 \mathrm{mg} & \text { In monthly groups: }>+8 \text { letters } \\ & \text { Monthly } \times 3 \text { of } & \text { VA improvement at } 8 \text { weeks: } \\ & 0.5 \mathrm{mg} & 2 \mathrm{mg} \mathrm{q} 4 \mathrm{wk}=2 \mathrm{mg} \mathrm{q} / 2 \mathrm{wk} \\ & 2 \mathrm{mg} & \end{array}$

Phase 2 Aflibercept: $\quad$ Mean $\Delta$ thickness at 52 wks: Intravitreal $\quad 159$ (same cohort $-130 \mu \mathrm{m}$ aflibercept as $0-12$ wks) (monthly $>$ single injections) 16-52 weeks All patients Mean $\triangle$ VA at 12 wks: +5.3 letters followed $q 4 w k \quad$ In initial monthly groups: and injected PRN > $>9$ letters

Average number of injections: 2 Patients receiving 0 injections: $19 \%$ Patients receiving I or 2 injections: $45 \%$

$\begin{array}{lll}\text { Phase 3 } & \text { Aflibercept and } & \text { Mean } \Delta \text { thickness at } 52 \text { wks: } \\ \text { (VIEW I and 2) } & \text { Ranbizumab: } & \text { VIEW I: }-218 \mu \mathrm{m} \text { to }-230 \mu \mathrm{m} \\ \text { Intravitreal } & 2457 \mathrm{pts} & \text { VIEW 2: }-130 \mu \mathrm{m} \text { to }-157 \mu \mathrm{m} \\ \text { aflibercept vs } & \text { Monthly } & \text { Mean } \Delta \text { VA at } 52 \text { wks: } \\ \text { ranibizumab } & \text { injections of } & \text { VIEW I: }+6.9 \text { letters to }+10.9 \\ \text { 0-52 weeks } & 0.5 \mathrm{mg} \text { aflibercept } & \text { letters } \\ & 2 \mathrm{mg} \text { aflibercept } & \text { VIEW 2: }+7.6 \text { letters to }+9.7 \\ & 0.5 \mathrm{mg} & \text { letters } \\ & \text { ranibizumab } & \\ & \text { Monthly } \times 3 \text { then } & \\ & \text { q8wk } & \\ & 2 \mathrm{mg} \text { aflibercept } & \end{array}$

Abbreviation: VIEW, Vascular Endothelial Growth Factor (VEGF) Trap-Eye: Investigation of Efficacy and Safety in Wet Age-Related Macular Degeneration Studies. 
Two concurrent Phase III trials, i.e. VIEW (Vascular Endothelial Growth Factor [VEGF] Trap-Eye: Investigation of Efficacy and Safety in Wet Age-Related Macular Degeneration Studies), enrolled 1217 patients from North America (VIEW 1) and 1240 patients from South America, Europe, Asia and Australia (VIEW 2). Patients were randomized $1: 1: 1: 1$ to receive ranibizumab $0.5 \mathrm{mg}$, aflibercept $0.5 \mathrm{mg}$, aflibercept $2 \mathrm{mg}$ every 4 weeks, or aflibercept $2 \mathrm{mg}$ every 8 weeks after three monthly loading doses.

All of the aflibercept arms in both trials achieved the primary endpoint, i.e. noninferiority compared with ranibizumab for maintenance of vision (decrease in vision less than 15 letters). Between $95 \%$ and $96 \%$ of patients in all study groups maintained vision, compared with $94 \%$ of patients in both ranibizumab groups. ${ }^{7}$ Gains in vision were comparable between patients in the aflibercept groups (+6.9 letters to +10.9 letters) and those receiving ranibizumab (+8.1 letters, +9.4 letters) but patients receiving aflibercept $2 \mathrm{mg}$ every 4 weeks in VIEW 1 gained more vision than those receiving ranibizumab $(+10.9$ letters versus +8.1 letters; $P=0.0054)$. However, when similarly treated arms from VIEW 1 and VIEW 2 were pooled, there was no appreciable difference in letters gained between patients receiving aflibercept $2 \mathrm{mg}$ every 4 weeks and those treated with ranibizumab. Similar proportions of patients in all treatment arms gained $>0$ letters and $>15$ letters.

Improvements in macular thickness, which ranged from $-218 \mu \mathrm{m}$ to $-230 \mu \mathrm{m}$ in VIEW 1 and from $-130 \mu \mathrm{m}$ to $-157 \mu \mathrm{m}$ in VIEW 2, were not statistically different among any of the treatment groups. Patients receiving aflibercept $2 \mathrm{mg}$ every 8 weeks in VIEW 2 showed bimonthly fluctuations in macular thickness, from $17 \mu \mathrm{m}$ early in the trial to $8 \mu \mathrm{m}$ by week 52 . However, no corresponding fluctuations in visual acuity were noted.

Both aflibercept and ranibizumab were well tolerated by patients in both trials. There were no significant differences between aflibercept and ranibizumab in the incidences of serious ocular adverse events $(1.6 \%$ and $2.3 \%$ versus $3.0 \%$ and $3.1 \%$, respectively) or systemic side effects $(1.6 \%$ and $1.9 \%$ versus $1.7 \%$ and $1.7 \%$ ).

Based on the one-year efficacy and safety results of the VIEW trials, the United States Food and Drug Administration approved the $2 \mathrm{mg}$ dose of aflibercept for the treatment of exudative AMD. The recommended treatment regimen includes three loading injections at 4-week intervals, followed by injections every 8 weeks.

During year 2 of the VIEW trials, patients continued receiving the same drug and dose as in year 1, were evaluated every 4 weeks, and were given injections as needed, but at intervals not exceeding 12 weeks. Between weeks 52 and 96, patients initially receiving aflibercept $2 \mathrm{mg}$ every 8 weeks and those initially receiving ranibizumab every 4 weeks maintained previous gains in vision $(+8.4$ letters $\rightarrow+7.6$ letters versus +8.7 letters $\rightarrow+7.9$ letters). ${ }^{113}$ Fewer patients receiving aflibercept required the most intensive treatments; $15.9 \%$ of patients initially receiving aflibercept and $26.5 \%$ of patients initially receiving ranibizumab required at least six injections, and $1.9 \%$ and $3.1 \%$ required at least 11 injections. Patients receiving aflibercept $2 \mathrm{mg}$ required an average of 4.2 injections, whereas patients receiving ranibizumab required an average of 4.7 injections. Forty-eight percent of patients receiving aflibercept $2 \mathrm{mg}$ and $40 \%$ of patients receiving ranibizumab received the minimum number (three) of injections.

Because aflibercept has been used for only a short period of time since approval, surgeons cannot accurately determine its durability, nor can they determine if the treatment interval can be extended beyond 8 weeks. However, the experience of the author and others (Philip Rosenfeld, personal communication, March 10,2012) suggests that aflibercept works remarkably well as "salvage" therapy. Administration of aflibercept to eyes with persistent fluid despite prolonged bevacizumab or ranibizumab therapy results in rapid resolution of subretinal fluid and flattening of pigment epithelial detachments (Figure 2).

\section{Place in therapy}

Following its approval for exudative AMD, aflibercept has entered a treatment landscape dominated by two drugs, ranibizumab and bevacizumab. Two pivotal trials, MARINA (The Minimally Classic/Occult Trial of the Anti-VEGF Antibody Ranibizumab in the Treatment of Neovascular AgeRelated Macular Degeneration) ${ }^{4}$ which evaluated patients with occult CNVM, and ANCHOR (The Anti-VEGF Antibody for the treatment of Predominantly Classic Choroidal Neovascularization in Age-Related Macular Degeneration) ${ }^{5}$ which evaluated patients with classic CNVM, showed that monthly injections of ranibizumab resulted in better visual gains compared with both sham injections $(+7.2$ letters versus -10.4 letters $)$ and photodynamic therapy $(+11.3$ letters versus -9.5 letters). These trials established monthly ranibizumab injections as the standard against which all subsequent randomized trials have been compared. However, despite the results of the MARINA and ANCHOR trials, nearly $60 \%$ of physicians prefer bevacizumab over ranibizumab. 

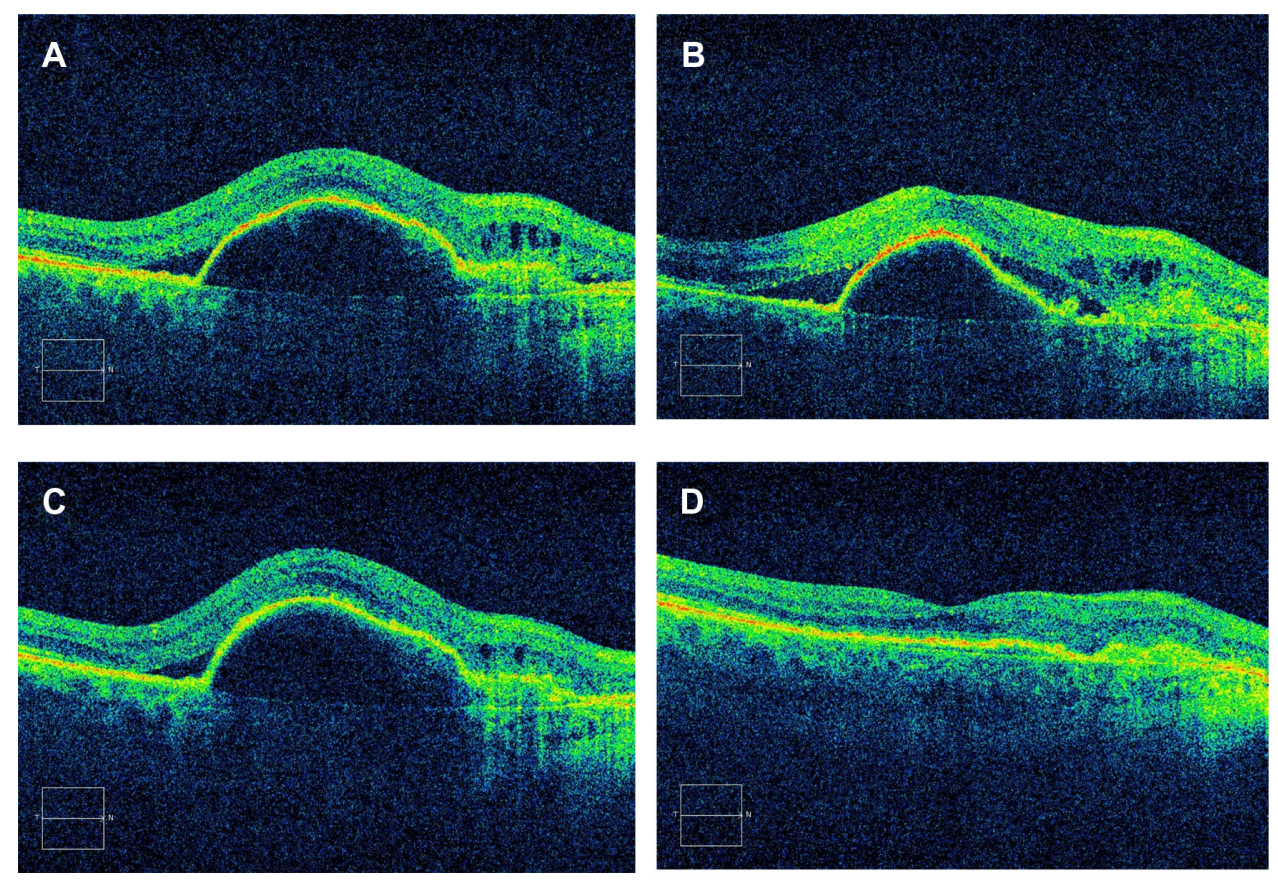

Figure 2 Sequential optical coherence tomography scans of patient's right eye show worsening subretinal fluid and an expanding retinal pigment epithelial detachment despite 6-monthly injections of bevacizumab (A) and (B). After one injection of aflibercept $2 \mathrm{mg}$, the subretinal fluid had decreased (C), and after the second injection of aflibercept, the subretinal fluid had resolved and the retinal pigment epithelial detachment had completely flattened (D).

CATT (the Complications of Age-related Macular Degeneration Treatment Trials) showed that monthly bevacizumab produced vision gains comparable with monthly ranibizumab (+8.0 letters versus +8.5 letters). ${ }^{6}$ Whereas improvements following PRN dosing of ranibizumab were not statistically different from monthly injections ( +6.8 letters versus +8.5 letters), PRN dosing of bevacizumab was termed "indeterminate" compared with monthly dosing (+5.9 letters versus +8.0 letters). Although the influence of the CATT results on physicians' choice of anti-VEGF drugs is not fully known, CATT investigators do not believe that many physicians have altered their drug preferences (Dan Martin, Retina 2012, Wailea, HI).

In addition to demonstrating the efficacy of aflibercept given every 4 or 8 weeks, the VIEW trials provided valuable information regarding peak efficacy and durability of antiVEGF therapy. Increasing the monthly dose of aflibercept from $0.5 \mathrm{mg}$ to $2 \mathrm{mg}$ did not appear to improve peak efficacy (maximum letters gained); similarly, the HARBOR trial showed that increasing the monthly dose of ranibizumab from $0.5 \mathrm{mg}$ to $2 \mathrm{mg}$ did not lead to further gains in vision $(+10.1$ letters versus +9.2 letters, Data on file, Genentech). These studies suggest that anti-VEGF monotherapy for exudative AMD has hit a therapeutic "ceiling" and that further gains in efficacy will require combination therapy with drugs that target other biological pathways.
Both trials suggest, but do not prove, that increasing the dose of a drug prolongs its duration of action (durability). The VIEW trials showed that aflibercept $2 \mathrm{mg}$ every 8 weeks produced vision gains comparable with aflibercept $0.5 \mathrm{mg}$ every 4 weeks $(+7.9$ and +8.9 letters versus +6.9 and +9.7 letters). Additionally, HARBOR showed that patients receiving PRN ranibizumab $0.5 \mathrm{mg}$ required 7.7 injections during the year whereas those receiving PRN ranibizumab $2 \mathrm{mg}$ required an average of 6.9 injections. These results are consistent with previously published models which predict that increasing the dose of an effective anti-VEGF drug has a greater effect on its durability than its efficacy. ${ }^{114}$

The price of bevacizumab ( $\$ 30-\$ 75$ US per dose) is much lower than that of ranibizumab (\$1950 US per dose). Physicians preferring bevacizumab because of its lower cost did so while believing that its efficacy was comparable with that of ranibizumab, and the results of CATT provided level 1 evidence to support this position. Other physicians prefer ranibizumab because of its excellent results in rigorous Phase III trials, on-label indications, and financial incentives. ${ }^{115}$

The price of aflibercept ( $\$ 1850$ US per dose) has been set just below that of ranibizumab, so for physicians following the treatment protocol used in the VIEW trials, i.e. three loading doses given at 4-week intervals followed by injections every 8 weeks, patient visits and injections will be half as 
frequent and will incur half the cost. Fewer injections should also decrease the cumulative incidence of ocular complications, including endophthalmitis.

However, most physicians employ a treat-and-observe (PRN) or treat-and-extend regimen, making it more difficult to estimate savings. Because year 2 of the VIEW trials used a 3-month capped PRN protocol, we do not know the expected duration of action of aflibercept after one year of regular injections. The data suggest that aflibercept would have lasted an average of approximately 3 months, probably 2-3 weeks longer than ranibizumab. Compared with ranibizumab, treat-and-observe with aflibercept would probably save 1-3 injections per year. However, compared with protocol-driven therapy, patients would probably receive eight fewer injections.

Now that aflibercept is available for AMD, physicians considering a change in drugs will need to consider several factors. For many physicians using ranibizumab because of the strength of its Phase III testing and on-label indication, switching to aflibercept with its expected longer duration of action is a reasonable strategy. Physicians will probably begin slowly, a few patients at a time, until they have accumulated sufficient experience. If the results obtained with post-approval use are similar to those seen in the VIEW trials, then this group of physicians will likely drift to aflibercept. Financial incentives (high-volume discounts, difference between wholesale price and Medicare reimbursement, and accrual of "airline miles" with credit card use) have influenced others to use ranibizumab instead of bevacizumab. Unless these incentives are reduced by either the government or the manufacturer, or matched by aflibercept, some physicians will continue to use ranibizumab for these reasons.

Whereas aflibercept has been approved only for the treatment of AMD, Phase III trials for diabetic macular edema and vein occlusions are ongoing. Ranibizumab has already received approval for vein occlusions and will likely receive approval for diabetic macular edema soon. Therefore, physicians will be using ranibizumab for new indications, and this familiarity will probably keep many using ranibizumab for AMD.

Despite the overall savings generated by aflibercept use (compared with ranibizumab), these cannot match the much lower total cost associated with bevacizumab therapy. Physicians preferring bevacizumab will now have the option of less frequent dosing with aflibercept, but at a higher overall cost. Although some physicians may switch drugs, predicting such a change is not possible.
A small number of eyes, referred to as "poor responders", significantly improve when the frequency of injections is increased from monthly to every 2 weeks. ${ }^{116}$ Early postapproval experience shows that switching from bevacizumab or ranibizumab to monthly injections of aflibercept frequently improves these difficult-to-treat eyes.

\section{Conclusion}

Aflibercept promises to decrease the frequency of injections for patients with exudative AMD. A slow shift by physicians from ranibizumab will decrease the number of patient visits to physicians' offices, decrease the overall cost of therapy, and improve patient satisfaction with AMD therapy. In the short term, physicians will notice a decrease in the burden of AMD patients in their offices. This reprieve will likely be short-lived because the continuing epidemic of exudative AMD patients will bring new patients to the offices for initiation of long-term therapy.

\section{Disclosure}

The author has served on an advisory board for Regeneron and his employer has received research support.

\section{References}

1. Ferris FL III, Fine SL, Hyman L. Age-related macular degeneration and blindness due to neovascular maculopathy. Arch Ophthalmol. 1984;102(11):1640-1642.

2. Macular Photocoagulation Study Group. Argon Laser photocoagulation for neovascular maculopathy. Arch Ophthalmol. 1986;104:694-701.

3. Treatment of Age-related Macular Degeneration with Photodynamic Therapy (TAP) Study Group. Verteporfin Therapy of Subfoveal Choroidal Neovascularization in Patients with Age-Related Macular Degeneration. Arch Ophthalmol. 2002;120:1443-1454.

4. Rosenfeld PJ, Brown DM, Heier JS, et al. Ranibizumab for age-related macular degeneration. N Engl J Med. 2006;355:1419-1431.

5. Brown DM, Kaiser PK, Michels M, et al. Ranibizumab versus verteporfin for neovascular age-related macular degeneration. $N$ Engl J Med. 2006;334:1432-1444.

6. Martin DF, Maguire MG, Ying G-S. Ranibizumab and bevacizumab for neovascular age-related macular degeneration. $N$ Engl $J$ Med. 2011;364(20):1897-1908.

7. http://investor.regeneron.com/releasedetail.cfm?ReleaseID $=532099$. Accessed March 19, 2012.

8. Bloch SB, Larsen M, Munch IC. Incidence of legal blindness from age-related macular degeneration in Denmark: year 2000-2010. Am J Ophthalmol. 2012;153(2):209-213.e2.

9. Macular Photocoagulation Study Group. Argon laser photocoagulation for neovascular maculopathy: five-year results from randomized clinical trials. Arch Ophthalmol. 1991;109:1109-1114.

10. Macular Photocoagulation Study Group. Laser photocoagulation for juxtafoveal choroidal neovascularization: five-year results from randomized clinical trials. Arch Ophthalmol. 1994;112:500-509.

11. Freund KB, Yannuzzi LA, Sorenson JA. Age-related macular degeneration and choroidal neovascularization. Am J Ophthalmol. 1993;115:786-791.

12. Bermig J, Tylla H, Jochmann C, et al. Angiographic findings in patients with exudative age-related macular degeneration. Graefes Arch Clin Exp Ophthalmol. 2002;240:169-175. 
13. Gass JD. Pathogenesis of disciform detachment of the neuroepithelium. Am J Ophthalmol. 1967;63(Suppl 1):S1-S139.

14. Green WR, Enger C. Age-related macular degeneration histopathologic studies: the 1992 Lorenz E. Zimmerman Lecture. Ophthalmology. 1993:100:1519-1535.

15. Green WR. Histopathology of age-related macular degeneration. Mol Vis. 1999;5:27-36.

16. Arjamaa O, Nikinmaa M, Salminen A, Kaarniranta K. Regulatory role of HIF- $1 \alpha$ in the pathogenesis of age-related macular degeneration (AMD). Ageing Res Rev. 2009;8:349-358.

17. Dunaief JL, Dentchev T, Ying G, Milam AH. The role of apoptosis in age-related macular degeneration. Arch Ophthalmol. 2002;120:1435-1442.

18. Stefansson E, Geirsdóttir A, Sigurdsson H. Metabolic physiology in age related macular degeneration. Prog Retin Eye Res. 2011;30:72-80.

19. Bressler NM, Bressler SB, Fine SL. Age-related macular degeneration. Surv Ophthalmol. 1988;32:375-413.

20. Loane E, Nolan JM, O'Donovan O, et al. Transport and retinal capture of lutein and zeaxanthin with reference to age-related macular degeneration. Surv Ophthalmol. 2008;53:68-71.

21. Tserentsoodol N, Sztein J, Campos M, et al. Uptake of cholesterol by the retina occurs primarily via a low density lipoprotein receptor-mediated process. Mol Vis. 2006;12:1306-1318.

22. Barnstable, Tombran-Tink J. Neuroprotective and antiangiogenic actions of PEDF in the eye: molecular targets and therapeutic potential. Prog Retin Eye Res. 2004;23:561-577.

23. Kim PK, Hailey DW, Mullen RT, Lippincott-Schwartz J. Ubiquitin signals autophagic degradation of cytosolic proteins and peroxisomes. Proc Nat Acad Sci USA. 2008;105:20567-20574.

24. Strauss $O$. The retinal pigment epithelium in visual function. Physiol Rev. 2005;85:845-881.

25. Algvere PV, Seregard S. Age-related maculopathy: pathogenetic features and new treatment modalities. Acta Ophthalmol Scand. 2002;80:136-143.

26. Delori FC, Goger DG, Dorey CK. Age-related accumulation and spatial distribution of lipofuscin in RPE of normal subjects. Invest Ophthalmol Vis Sci. 2001;42:1855-1866.

27. Sparrow JR, Cai B, Fishkin N, et al. A2E, a fluorophore of RPE lipofuscin: can it cause RPE degeneration? Adv Exp Med Biol. 2003;533:205-211.

28. Warburton S, Southwick K, Hardman RM, et al. Examining the proteins of functional retinal lipofuscin using proteomic analysis as a guide for understanding its origin. Mol Vis. 2005;11:1122-1134.

29. Bindewald A, Bird AC, Dandekar SS, et al. Classification of fundus autofluorescence patterns in early age-related macular disease. Invest Ophthalmol Vis Sci. 2005;46:3309-3314.

30. Holz FG, Bindewald-Wittich A, Fleckenstein M, and FAM-Study Group. Progression of geographic atrophy and impact of fundus autofluorescence patterns in age-related macular degeneration. Am J Ophthalmol. 2007; $143: 463-472$.

31. Ruberti JW, Curcio CA, Millican CL, et al. Quick-freeze/deep-etch visualization of age-related lipid accumulation in Bruch's membrane. Invest Ophthalmol Vis Sci. 2003;44:1753-1759.

32. Huang JD, Presley JB, Chimento MF, et al. Age-related changes in human macular Bruch's membrane as seen by quick-freeze/deep-etch. Exp Eye Res. 2007;85:202-218.

33. Holz FG, Sheraidah G, Pauleikhoff D, et al. Analysis of lipid deposits extracted from human macular and peripheral Bruch's membrane. Arch Ophthalmol. 1994;112:402-406.

34. Nordgaard CL, Karunadharma PP, Feng X, Olsen TW, Ferrington DA. Mitochondrial proteomics of the retinal pigment epithelium at progressive stages of age-related macular degeneration. Invest Ophthalmol Vis Sci. 2008;49:2848-2855.

35. Hartl FU. Molecular chaperones in cellular protein folding. Nature. 1996;381:571-579.

36. Hartl FU, Hayer-Hartl M. Molecular chaperones in the cytosol: from nascent chain to folded protein. Science. 2002;295:1852-1858.
37. Kopito RR. Aggresomes, inclusion bodies and protein aggregation. Trends Cell Biol. 2000;10:524-530.

38. Wojcik C. Regulation of apoptosis by the ubiquitin and proteosome pathway. J Cell Mol Med. 2002;6:25-48.

39. Kaarniranata K, Salminen A, Eskelinen E, Kopitz J. Heat shock proteins as gatekeepers of proteolytic pathways - implications for age-related macular degeneration (AMD). Ageing Res Rev. 2009;8:128-139.

40. Wassell J, Davies S, Bardsley W, Boulton M. The photoreactivity of the retinal age pigment lipofuscin. J Biol Chem. 1999;274:23828-23832.

41. Holz F, Schutt F, Kopitz J, et al. Inhibition of lysosomal degradative functions in RPE cells by a retinoid component of lipofuscin. Invest Ophthalmol Vis Sci. 1999;40:737-743.

42. Javitt NB, Javitt JC. The retinal oxysterol pathway: a unifying hypothesis for the cause of age-related macular degeneration. Curr Opin Ophthalmol. 2009;20:151-157.

43. Crabb JW, Miyagi M, Gu X, et al. Drusen proteome analysis: an approach to the etiology of age-related macular degeneration. Proc Natl Acad Sci USA. 2002;99:14682-14687.

44. Howes KA, Liu Y, Dunaief JL, et al. Receptor for advanced glycation end products and age-related macular degeneration. Invest Ophthalmol Vis Sci. 2004;45:3714-3720.

45. Oskolkova OV, Afonyushkin T, Leitner A, et al. ATF4-dependent transcription is a key mechanism in VEGF up-regulation by oxidized phospholipids: critical role of oxidized sn-2 residues in activation of unfolded protein response. Blood. 2008;112:330-339.

46. Elner SG, Petty HR, Elner VM, et al. TLR4 mediates human retinal pigment epithelial endotoxin binding and cytokine expression. Invest Ophthalmol Vis Sci. 2005;46:4627-4633.

47. Ebihara N, Chen L, Tokura T, Ushio H, Iwatsu M, Murakami A. Distinct functions between toll-like receptors 3 and 9 in retinal pigment epithelial cells. Ophthalmic Res. 2007;39:155-163.

48. Kumar MV, Nagineni CN, Chin MS, Hooks JJ, Detrick B. Innate immunity in the retina: toll-like receptor (TLR) signaling in human retinal pigment epithelial cells. J Neuroimmunol. 2004;153:7-15.

49. Kindzelskii AL, Elner VM, Elner SG, Yang D, Hughes BA, Petty HR. Toll-like receptor 4 (TLR4) of retinal pigment epithelial cells participates in trans-membrane signaling in response to photoreceptor outer segments. J Gen Physiol. 2004;124:139-149.

50. Paimela T, Ryhänen T, Mannermaa E, et al. The effect of $17 \beta$-estradiol on IL-6 secretion and NF-kB DNA-binding activity in human retinal pigment epithelial cells. Immunol Lett. 2007;110;139-144.

51. Holtkamp GM, Kijlstra A, Peek R, de Vos AF. Retinal pigment epithelium-immune system interactions: cytokine production and cytokineinduced changes. Prog Retin Eye Res. 2001;20:29-48.

52. Yang D, Elner SG, Bian Z, et al. Pro-inflammatory cytokines increase reactive oxygen species through mitochondria and NADPH in cultured RPE cells. Exp Eye Res. 2007;85:462-472.

53. Salminen A, Kauppinen A, Hyttinen JM, Totopainen E, Kaarniranta $\mathrm{K}$. Endoplasmic reticulum stress in age-related macular degeneration: trigger for neovascularization. Mol Med. 2010;16:535-542.

54. Hageman GS, Luthert PJ, Victor Chong NH, Johnson LV, Anderson DH, Mullins RF. An integrated hypothesis that considers drusen as biomarkers of immune-mediated processes at the RPE-Bruch's membrane interface in aging and age-related macular degeneration. Prog Retin Eye Res. 2001;20:705-732.

55. Penfold PL, Provis JM, Furby JH, Gatenby PA, Billson FA. Autoantibodies to retinal astrocytes associated with age-related macular degeneration. Graefes Arch Clin Exp Ophthalmol. 1990;228:270-274.

56. Gurne DH, Tso MO, Edward DP, Ripps H. Antiretinal antibodies in serum of patients with age-related macular degeneration. Ophthalmology. 1991;98:602-607.

57. Killingsworth MC, Sarks JP, Sarks SH. Macrophages related to Bruch's membrane in age-related macular degeneration. Eye. 1990;4:613-621.

58. Oh $\mathrm{H}$, Takagi $\mathrm{H}$, Takagi $\mathrm{C}$, et al. The potential angiogenic role of macrophages in the formation of choroidal neovascular membranes. Invest Ophthalmol Vis Sci. 1999;40:1891-1898. 
59. Frank RN, Amin RH, Eliott D, et al. Basic fibroblast growth factor and vascular endothelial growth factor are present in epiretinal and choroidal neovascular membranes. Am J Ophthalmol. 1996;122:393-403.

60. Amin R, Puklin JE, Frank RN. Growth factor localization in choroidal neovascular membranes of age-related macular degeneration. Invest Ophthalmol Vis Sci. 1994;35:3178-3188.

61. Soubrane G, Cohen SY, Delayre T, et al. Basic fibroblast growth factor experimentally induced choroidal angiogenesis in the minipig. Curr Eye Res. 1994;13:183-195.

62. Kimura H, Sakamoto T, Hinton DR, et al. A new model of subretinal neovascularization in the rabbit. Invest Ophthalmol Vis Sci. 1995;36:2110-2119.

63. Tobe T, Ortega S, Luna JD, et al. Targeted disruption of the FGF2 gene does not prevent choroidal neovascularization in a murine model. Am J Pathol. 1998;153:1641-1646.

64. Bouck N. PEDF anti-angiogenic guardian of ocular function. Trends Mol Med. 2002;8:330-334.

65. Duh EJ, Yang HS, Suzuma I, et al. Pigment epithelium-derived factor suppresses ischemia-induced retinal neovascularization and VEGF-induced migration and growth. Invest Ophthalmol Vis Sci. 2002;43:821-829.

66. Mori K, Gehlbach P, Ando A, et al. Regression of ocular neovascularization in response to increased expression of pigment epithelium-derived factor. Invest Ophthalmol Vis Sci. 2002;43:2428-2434.

67. Dawson DW, Volpert OV, Gillis P, et al. Pigment epithelium-derived factor: a potent inhibitor of angiogenesis. Science. 1999;285:245-248.

68. Ogata N, Nishikawa M, Nishimura T, et al. Inverse levels of pigment epithelium-derived factor and vascular endothelial growth factor in the vitreous of eyes with rhegmatogenous retinal detachment and proliferative vitreoretinopathy. Am J Ophthalmol. 2002;133:851-852.

69. Ohno-Matsui K, Morita I, Tombran-Tink J, et al. Novel mechanism for age-related macular degeneration: an equilibrium shift between the angiogenesis factors VEGF and PEDF. $J$ Cell Physiol. 2001;189:323-333.

70. Renno RZ, Youssri AI, Michaud N, et al. Expression of pigment epithelium-derived factor in experimental choroidal neovascularization. Invest Ophthalmol Vis Sci. 2002;43:1573-1580.

71. Yancopoulos GD, Davis S, Gale NW, et al. vascular-specific growth factors and blood vessel formation. Nature. 2000;407:242-248.

72. Thurston G, Rudge JS, Ioffe E, et al. Angiopoietin-1 protects the adult vasculature against plasma leakage. Nat Med. 2000;6:460-463.

73. Oh H, Takagi H, Suzuma K, et al. Hypoxia and vascular endothelial growth factor selectively upregulate angiopoietin-2 in bovine microvascular endothelial cells. J Biol Chem. 1999;274:15732-15739.

74. Green WR, Enger C. Age-related macular degeneration histopathologic studies: the 1992 Lorenz E. Zimmerman Lecture. Retina. 2005;25:1519-1535.

75. Green WR, Key SN 3rd. Senile macular degeneration: a histopathologic study. 2005;25:180-250.

76. Ambati J, Ambati BK, Yoo SH, Ianchulev S, Adamis AP. Age-related macular degeneration: etiology, pathogenesis, and therapeutic strategies. Surv Ophthalmol. 2003;48:257-293.

77. Grossniklaus HE, Martinez JA, Brown VB, et al. Immunohistochemical and histochemical properties of surgically excised subretinal neovascular membranes in age-related macular degeneration. Am J Ophthalmol. 1992;114:464-472.

78. Frank RN, Amin RH, Eliott D, et al. Basic fibroblast growth factor and vascular endothelial growth factor are present in epiretinal and choroidal neovascular membranes. Am J Ophthalmol. 1996;122:393-403.

79. Kvanta A, Algvere PV, Berglin L, et al. Subfoveal fibrovascular membranes in age-related macular degeneration express vascular endothelial growth factor. Invest Ophthalmol Vis Sci. 1996;37:1929-1934.

80. Lopez PF, Sippy BD, Lambert HM, et al. Trans-differentiated retinal pigment epithelial cells are immunoreactive for vascular endothelial growth factor in surgically excised age-related macular degenerationrelated choroidal neovascular membranes. Invest Ophthalmol Vis Sci. 1996;37:855-868.
81. Baffi J, Byrnes G, Chan CC, et al. Choroidal neovascularization in the rat induced by adenovirus mediated expression of vascular endothelial growth factor. Invest Ophthalmol Vis Sci. 2000;41:3582-3589.

82. Schwesinger C, Yee C, Rohan RM, et al. Intrachoroidal neovascularization in transgenic mice overexpressing vascular endothelial growth factor in the retinal pigment epithelium. Am J Pathol. 2001;158:1161-1172.

83. Spilsbury K, Garrett KL, Shen WY, et al. Overexpression of vascular endothelial growth factor (VEGF) in the retinal pigment epithelium leads to the development of choroidal neovascularization. Am J Pathol. 2000;157:135-144.

84. Wells JA, Murthy R, Chibber R, et al. Levels of vascular endothelial growth factor are elevated in the vitreous of patients with subretinal neovascularization. Br J Ophthalmol. 1996;80:363-366.

85. Holekamp NM, Bouck N, Volpert O. Pigment epithelium-derived factor is deficient in the vitreous of patients with choroidal neovascularization due to age-related macular degeneration. Am JOphthalmol. 2002;134:220-227.

86. Ferrara N. Vascular endothelial growth factor: basic science and clinical progress. Endocr Rev. 2004;25(4):581-611.

87. Senger DR, Galli SJ, Dvorak AM, Perruzzi CA, Harvey VS, Dvorak HF. Tumor cells secrete a vascular permeability factor that promotes accumulation of ascites fluid. Science. 1983;219:983-985.

88. Ferrara N, Gerber H, LeCouter J. The biology of VEGF and its receptors. Nat Med. 2003;9:669-676.

89. Terman BI, Dougher-Vermazen M, Carrion ME, et al. Identification of the KDR tyrosine kinase as a receptor for vascular endothelial cell growth factor. Biochem Biophys Res Commun. 1992;187:1579-1586.

90. Witmer AN, Vrensen GF, Van Noorden CJ, et al. Vascular endothelial growth factors and angiogenesis in eye disease. Prog Retin Eye Res. 2003;22:1-29.

91. Blaauwgeers HGT, Holtkamp GM, Rutten H, et al. Polarized vascular endothelial growth factor secretion by human retinal pigment epithelium and localization of vascular endothelial growth factor receptors on the inner choriocapillaris: evidence for a trophic paracrine relation. Am J Pathol. 1999;155:421-428.

92. Miller JW, Adamis AP, Aiello LP. Vascular endothelial growth factor in ocular neovascularization and proliferative diabetic retinopathy. Diabetes Metab Rev. 1997;13:37-50.

93. Kuroki M, Voest EE, Amano S, et al. Reactive oxygen intermediates increase vascular endothelial growth factor expression in vitro and in vivo. J Clin Invest. 1996;98:495-504.

94. Lu M, Kuroki M, Amano S, et al. Advanced glycation end products increase retinal vascular endothelial growth factor expression. J Clin Invest. 1998;101:1219-1224.

95. Papapetropoulos A, Garcia-Cardeña G, Madri JA, Sessa WC. Nitric oxide production contributes to the angiogenesis properties of vascular endothelial growth factor in human endothelial cells. $J$ Clin Invest. 1997; 100:3131-3139.

96. Lamoreaux WJ, Fitzgerald ME, Reiner A, et al. Vascular endothelial growth factor increases release of gelatinase A and decreases release of tissue inhibitor of metalloproteinases by microvascular endothelial cells in vitro. Microvasc Res. 1998;55:29-42.

97. Mott JD, Werb Z. Regulation of matrix biology by matrix metalloproteinases. Curr Opin Cell Biol. 2004;16:558-564.

98. Kim I, Ryan A, Rohan R, et al. Constitutive expression of VEGF, VEGFR-1, and VEGFR-2 in normal eyes. Invest Ophthalmol Vis Sci. 1999;40:2115-2121.

99. Alon T, Hemo I, Itin A, et al. Vascular endothelial growth factor as a survival factor for newly formed retinal vessels and has implications for retinopathy of prematurity. Nat Med. 1995;1:1024-1028.

100. Papadopoulos N, Martin J, Ruan Q, et al. Binding and neutralization of vascular endothelial growth factor (VEGF) and related ligands by VEGF Trap, ranibizumab and bevacizumab. Angiogenesis. 2012;DOI 10.1007/s10456-011-9249-6.

101. Holash J, Davis S, Papadopoulos N, et al. VEGF-Trap: a VEGF blocker with potent antitumor effects. PNAS. 2002;99(17):11392-11398. 
102. Stewart MW. What are the half-lives of ranibizumab and aflibercept (VEGF Trap-eye) in human eyes? Calculations with a mathematical model. Eye Reports. 2011;1:e5.

103. Stewart MW, Rosenfeld PJ. Predicted biological activity of intravitreal VEGF Trap. Br J Ophthalmol. 2008;92(5):667-668.

104. Dixon JA, Oliver, Olson JL, Mandava N. VEGF Trap-eye for the treatment of age-related macular degeneration. Expert Opin Investig Drugs. 2009;18(10):1573-1580.

105. Cao J, Zhao L, Li Y, et al. A subretinal matrigel rat choroidal neovascularization (CNV) model and inhibition of CNV and associated inflammation and fibrosis by VEGF Trap. Invest Ophthalmol Vis Sci. 2010;51(11):6009-6017.

106. Saichin Y, Takahashi K, Lima e Silva R, et al. VEGF-TRAP(R1R2) suppresses choroidal neovascularization and VEGF-induced breakdown of the blood-retinal barrier. J Cell Physiol. 2003;195:241-248.

107. Cursiefen C, Chen L, Borges LP, et al. VEGF-A stimulates lymphangiogenesis and hemangiogenesis in inflammatory neovascularization via macrophage recruitment. J Clin Invest. 2004;113:1040-1050.

108. Oliviera HB, Sakimoto T, Javier JAD, et al. VEGF Trap ${ }_{\mathrm{R} 1 \mathrm{R} 2}$ suppresses experimental corneal angiogenesis. Eur J Ophthalmol. 2010;20:48-54.

109. Nguyen QD, Shah SM, Hafiz G, et al. A phase I trial of an IVadministered vascular endothelial growth factor trap for treatment in patients with choroidal neovascularization due to age-related macular degeneration. Ophthalmology. 2006;113:1522-1532.
110. Nguyen QD, Shah SM, Browning DJ, et al. A phase I study of intravitreal vascular endothelial growth factor trap-eye in patients with neovascular age-related macular degeneration. Ophthalmology. 2009;116:2141-2148.

111. Brown DM, Heier JS, Ciulla T, et al. Primary endpoint results of a phase II study of vascular endothelial growth factor trap-eye in wet age-related macular degeneration. Ophthalmology. 2011;118:1089-1097.

112. Heier JS, Boyer D, Nguyen QD, et al. The 1-year results of CLEARIT 2, a phase 2 study of vascular endothelial growth factor trapeye dosed as-needed after 12-week fixed dosing. Ophthalmology. 2011;118:1098-1106.

113. Two Year Results of Phase 3 Studies with EYLEA ${ }^{\mathrm{TM}}$ (aflibercept) Injection in wet AMD Show Sustained Improvement in Visual Acuity. http://investor.regeneron.com/releasedetail.cfm?ReleaseID $=629800$. Accessed 4/13/2012.

114. Gaudreault J, Fei D, Rusit J, Suboc P, Shiu V. Preclinical pharmacokinetics of ranibizumab (rhuFabV2) after a single intravitreal administration. Invest Ophthalmol Vis Sci. 2005;46(2):726-733.

115. A Prescription for Savings: Reducing Drug Costs to Medicare. http:// aging.senate.gov/events/hr236pr.pdf. Accessed 4/13/2012.

116. Stewart MW, Rosenfeld PJ, Penha FM, et al. Pharmacokinetic rationale for dosing every 2 weeks versus 4 weeks with intravitreal ranibizumab, bevacizumab, and aflibercept (vascular endothelial growth factor trap-eye). Retina. 2012;32(3):343-457.
Clinical Ophthalmology

\section{Publish your work in this journal}

Clinical Ophthalmology is an international, peer-reviewed journal covering all subspecialties within ophthalmology. Key topics include: Optometry; Visual science; Pharmacology and drug therapy in eye diseases; Basic Sciences; Primary and Secondary eye care; Patient Safety and Quality of Care Improvements. This journal is indexed on

\section{Dovepress}

PubMed Central and CAS, and is the official journal of The Society of Clinical Ophthalmology (SCO). The manuscript management system is completely online and includes a very quick and fair peer-review system, which is all easy to use. Visit http://www.dovepress.com/ testimonials.php to read real quotes from published authors. 